\title{
An Inspection of Some Hydrogenated Carbon Fibers by Scanning Electron Microscopy and Confocal Laser Scanning Microscopy
}

\author{
Antonio Madroñero ${ }^{1}$ and Jose $\mathrm{M}^{\mathrm{a}} \mathrm{Amo}^{2}$ \\ ${ }^{1}$ Centro Nacional de Investigaciones Metalúrgicas \\ ${ }^{2}$ Consejo Superior de Investigaciones Científicas \\ Spain
}

\section{Introduction}

The huge and rapid development of hydrogen technology has led to great attention being paid to hydrogen absorbent carbonaceous materials (Dillon and Heben, 2001).

Because of this, all families of carbonaceous materials have been separately examined with the intention to clarify the physical mechanisms of the adsorption of hydrogen, looking for the possibility to optimize their capacity of hydrogen storage (Alcañiz-Monge and RomanMartinez, 2008). Particularly, the carbonaceous nanostructures have been studied from the point of view of the location of adsorbed hydrogen atoms, the storage mechanisms, and the kinetic of adsorption/desorption (Nechaev, 2006). According to these studies, the carbonaceous nanostructures show to have a limited capacity of hydrogen storage only.

Interesting works have been conducted to establish the details that describe hydrogen insertion in carbonous absorbents. On the one hand, models consisting of the absorption and penetration of molecular hydrogen through the carbon network have been conducted (Seifert, 2004). On the other hand, other studies stress that the amount of absorbed hydrogen per weight depends on the micropore volume of the sample (Takagi et al., 2004). This indicates the importance of being able to examine the surface of the carbonous materials to determine the hydrogen housing locations.

For this study, we have selected vapor grown carbon fibers (VGCFs) as the carbonous material. The fibers were prepared via catalyzed decomposition of a gaseous hydrocarbon that produced a solid carbon deposit in the form of filaments. The germination and growth mechanism is explained as a vapor-liquid-solid (VLS) process (Gorbunov et al., 2002, Madroñero, 1995). Minute ferrocene crystals were utilized as germs to initiate fiber growth, as explained by (Serp et al, 1999). By using this growth method, the iron germ binds to the substrate and the fiber grows as a liquid drop on its tip; in this way, what can be expected is that the fiber will remain free of iron impurities.

Therefore, we have checked that the fibers utilized in this work do not contain iron in spite of them have been developed using ferric seeds (ferrocene). To this end, we have conducted their analysis via inductively coupled plasma mass spectrometry (ICP-MS) with Perkin Elmer ${ }^{\circledR}$ SCIEX ELAN 6000 equipment. Significant values for iron content were not obtained, with the determination limit of the technique, under the utilized working conditions, being $0.1 \mathrm{ppm}$. 
The fibers thus obtained with cylindrical morphology comprise two carbonous phases. There is a central portion of greater crystalline perfection, and a peripheral portion of a more amorphous nature, as can be seen in figure 2.b. Therefore the structure of these fibers was labeled as sword in sheath (Madroñero et al., 1997).

The results of the above studies indicate that solid aromatic hydrocarbons, at the end of the solid hydrocarbon list, are capable of absorbing and storing hydrogen in a uniform manner (Denis, 2008). As the cortical layer of the fibers utilized in this work is formed partially by hydrocarbons of this type, the results of the aforementioned studies establishing that these types of fibers could store significant quantities of hydrogen are perfectly reasonable (Madroñero et al., 1995).

\section{Experimental}

\subsection{Preparation of the fiber samples}

The fibers were fabricated in a vertical oven formed by a $10 \mathrm{~cm}$ diameter quartz pipe where some strays or substrates were placed vertically, and where some minute grains of ferrocene were then placed. A mixture of $70 \%$ hydrogen and 30\% methane flowed from the lower section of the oven to the outlet located in the upper section. Thus, the gas passed through the substrates, fostering growth of the carbon microfibers. The process temperature was $1,300 \mathrm{~K}$. The details of the process are given by (Serp et al., 1999).

Subsequently, the density of these fibers was measured with a Micromeritics ${ }^{\circledR}$ make, Accupyc 1330 model gas pycnometer.

Figure 1. shows the cylindrical morphology of these fibers that, as a consequence of the VLS process that occurred during their growth, show continuous changes in the direction of the progression of the fiber tip. It is therefore a discontinuous growth, pursuant to a pull sequence.

In this work, a very simple inspection technique has been selected, consisting of subjecting the fibers to an oxidation process in air; this operation was conducted in the same oven as was utilized to produce the fibers. The oxidation temperature was $973 \mathrm{~K}$ with a 0.090 $\mathrm{mol} / \mathrm{min}$ air flow and variable oxidation times ranging between 2 and $15 \mathrm{~min}$.

With this superficial oxidation attacks were being made, preferably in the areas that were richest in hydrogen, given that we know that the oxidation of carbonous materials is greatly affected by the hydrogen content of the material (Zhou and McGinn, 2006). Moreover, and considering that oxidation is very active over time, successive layers of the material were progressively removed so that observation by SEM and CLSM microscopy allows appreciation of the locations of the hydrogen stored in the structure of the cortical layer in shallow layers, and not only on the surface. These techniques were utilized previously (Merino and Brandl, 2003).

The fabricated fibers have been divided up in order to conduct this study on two types of material. The first group is simply the grown VGCF fibers, without any type of superficial treatment; they showed a density of $1.419 \mathrm{~g} / \mathrm{cm}^{3}$.

The fibers of the second group were subjected to a careful annealing process to eliminate absorbed molecules that could interfere with the hydrogen (Park et al., 1999). After that, these fibers were subsequently subjected to annealing at $1,473 \mathrm{~K}$ and $0.510^{-3}$ bar with residual atmosphere of Ar. They had a density of $1,459 \mathrm{~g} / \mathrm{cm}^{3}$ and were labeled as "discharged fibers". 

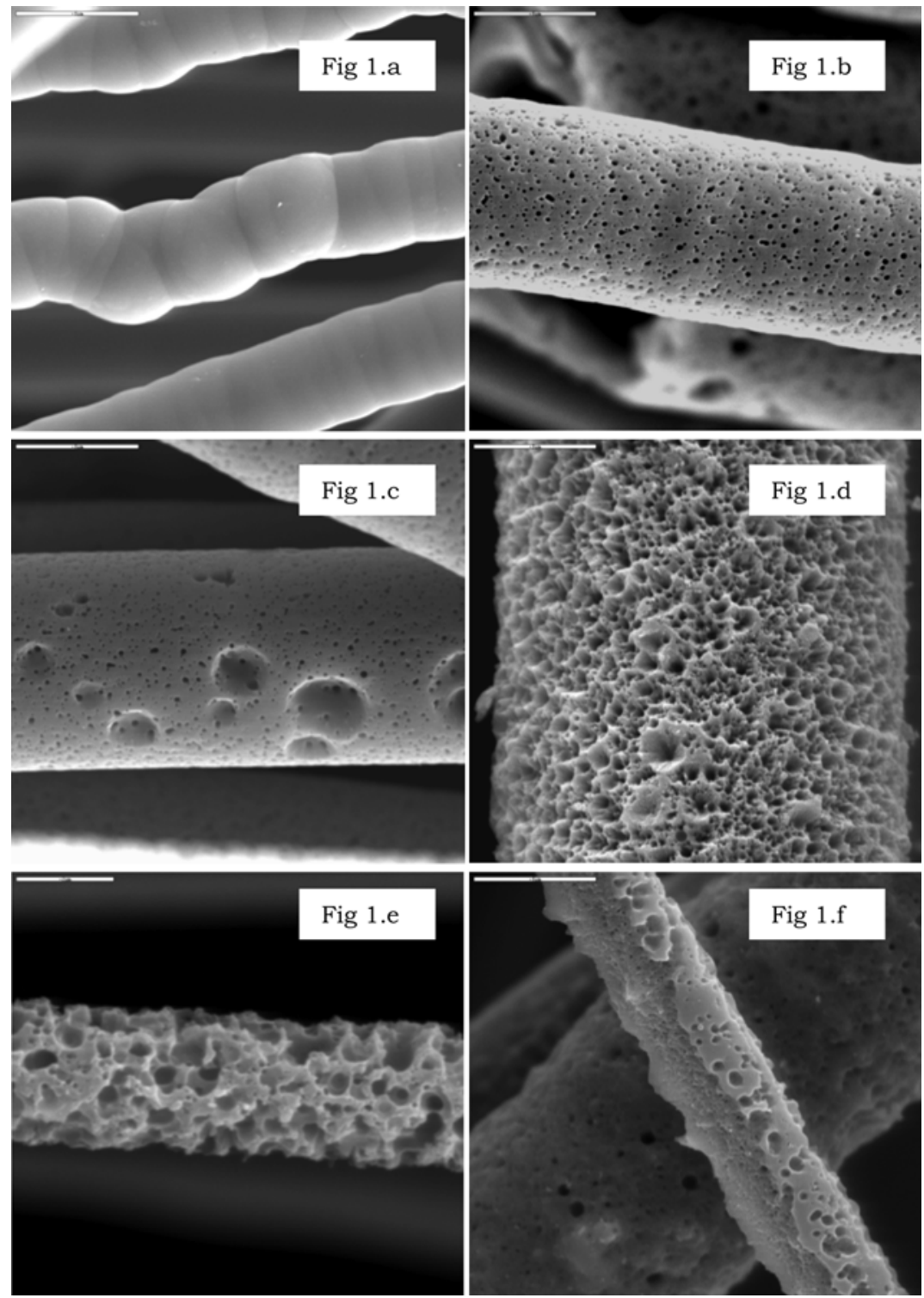

Fig. 1. Oxidation effects in as grown fibres observed by SEM. Scale bars: 1a, 1b, 1c, 1d, 1f = 5 $\mu \mathrm{m} ; 1 \mathrm{e}=2 \mu \mathrm{m}$ 


\subsection{Characterization of the fibers by microscopy}

\subsubsection{Differences between an inspection of the fibers by SEM and by CLSM}

SEM inspection is customary in these types of studies as it allows an image of the surface of fibers that show an increasing degree of erosion in such a way that with the entire array of all the images (see Fig. 1), the location of the accumulations of hydrogen on ever more interior layers can be identified. This is because annealing occurs simultaneously to the oxidation process and its effect is the formation of small pittings that mark the point where an accumulation of hydrogen, which had subsequently escaped leaving an empty space, had occurred.

The utilization of CLSM together with SEM has been successfully proven in cases of tracking of the alteration that occurs on some surfaces (Yamada et al., 2004). Results of the utilization of CLSM by reflection with laser light on inspection of glass fibers are known (Clarke and Davidson, 1993). The intensity of the reflected light depends on the angle of reflection and, moreover, thanks to the transparency of glass, the radiation penetrates into the cortical zone and a very interesting $3 \mathrm{D}$ image is obtained.

The thickness of the cortical layer [15] is obtained from:

$$
d_{z}=\frac{0.45 \lambda}{1-\cos \theta}
$$

where $\lambda$ is the wavelength of the laser radiation utilized, and $\theta$ is the angle of reflection.

In the case of VGCF, formed by carbon, what is to be expected is that the radiation can penetrate the thin carbonous layers (Veersamy et al., 2003) with a refraction index that depends on the proportion of $\mathrm{sp}^{2}$ and $\mathrm{sp}^{3}$ links, and therefore, what can be expected is that the CLSM will be capable of observing the cortical layer of the fibers, unlike the SEM which is only going to provide us with an image of the surface.

\subsubsection{Inspection via SEM}

The inspection was performed with Zeiss ${ }^{\circledR}$ model 960 equipment. The VGCF for this study were installed on sample trays subsequently plated with gold in an evaporator.

2.2.2.1 SEM inspection of VGCF fibers labeled as "grown".

Fig. 1.a shows the aspect of said fibers in initial state, from which they will be subjected to a $973 \mathrm{~K}$ oxidation process with different treatment times.

After an oxidation time of 2 minutes (see Fig. 1.b.) the outer picture of the fiber shows regular and uniform distribution of multiple pittings that appear to be sized from 0.04 to $0.16 \mu \mathrm{m}$.

The aspect of the fibers for which the oxidation time is extended to 4 minutes, the aspect of the fibers is shown in Fig. 1.c.; these fibers in addition to the pittings shown in the previous figure, have pittings that are slightly increased in size and large pittings $2 \sim 3 \mu \mathrm{m}$. And so we can assume that they have another formation mechanism.

When 8 minutes of oxidation is reached, the surface, as shown in Fig. 1.d., shows that all the pittings grew until the entire surface had been covered. We can still observe the pittings that were visible after 2 minutes of oxidation as well as those corresponding to the large pittings that appear in Fig. 1.c.

The carbonaceous material elimination process reaches its final stage in the state generated by 10 -minute oxidation, as indicated in Fig. 1.e. 
Fig. 1.f. shows that the matter removal process finishes when the cortical layer of the fiber has been eliminated. For more extended oxidation times, the nucleus will present a slower and more uniform attack without the large pittings that act as a cortical layer destruction mechanism, as we have seen in the previous pictures.

\subsubsection{SEM inspection of the discharged fibers}

Fig. 2.a. shows the initial state of the fibers we have labeled as "discharged".
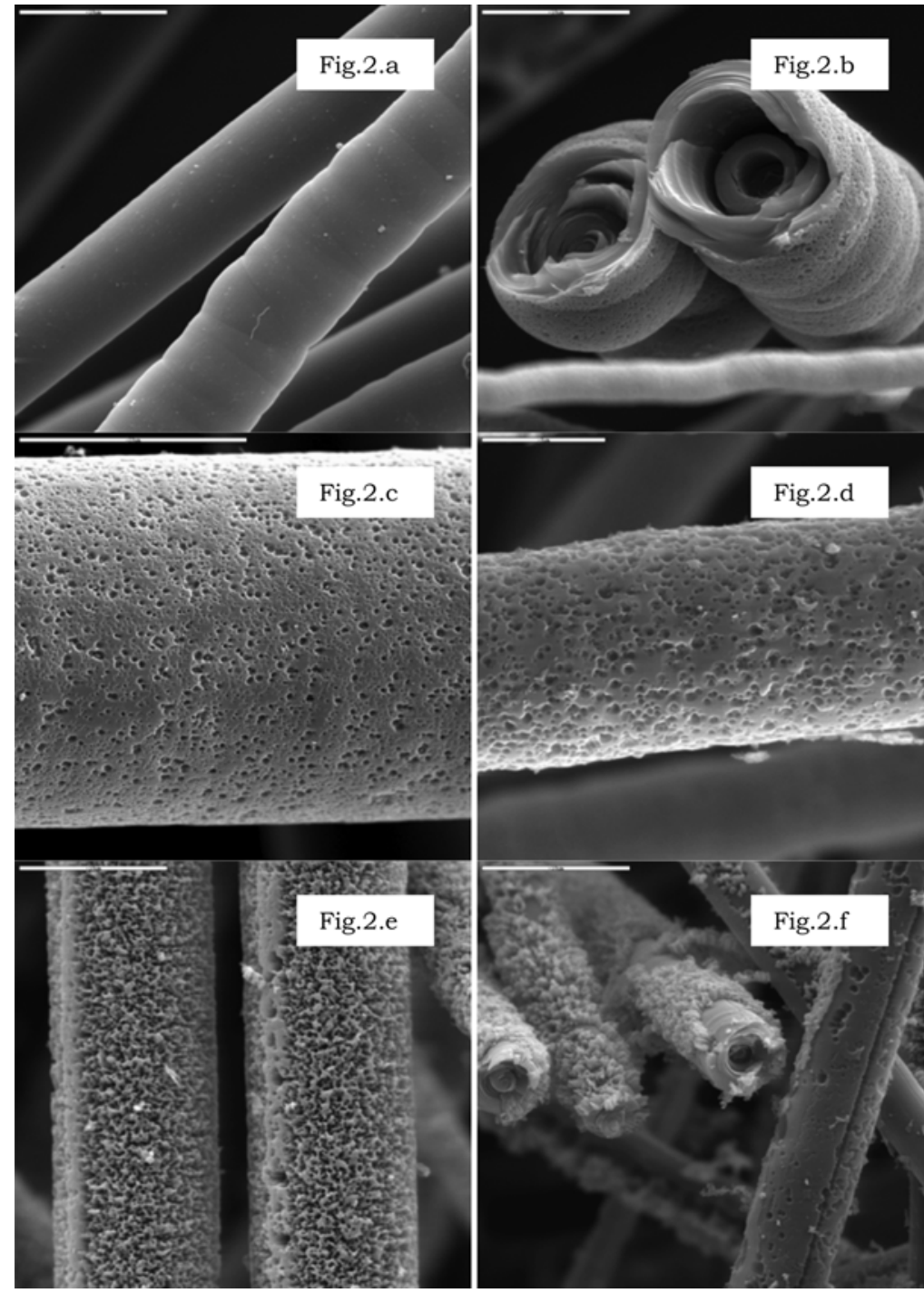

Fig.2.d
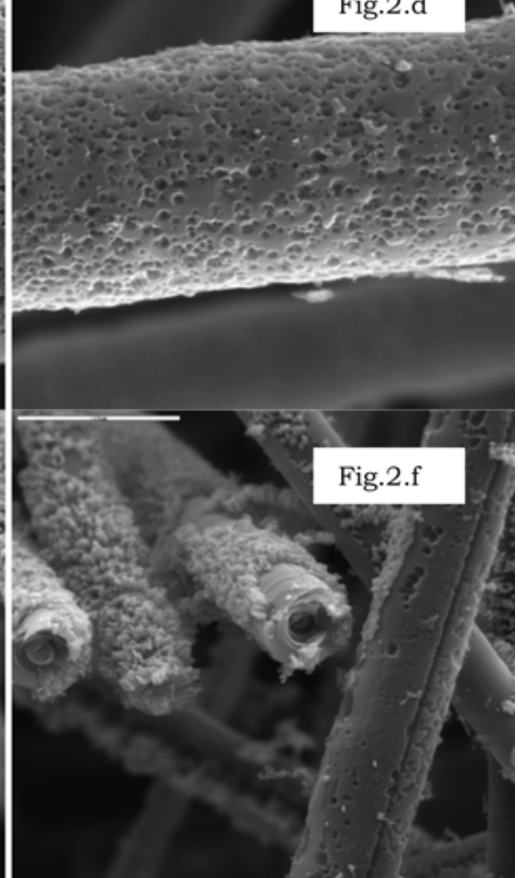

Fig. 2. Oxidation effects in annealed fibres observed by SEM. Scale bars: $2 a, 2 b, 2 e, 2 f,=10$ $\mu \mathrm{m} ; 2 \mathrm{c}=20 \mu \mathrm{m} ; 2 \mathrm{~d}=5 \mu \mathrm{m}$ 
Figure 2.b. shows the aspect of the fibers in a situation equivalent to those that had been shown in figure 1.b. The same appearance of small uniformly distributed pittings can be seen.

When 4 minutes have passed, the oxidation process shows differences to the "grown" fibers as can be seen if we compare Fig. 2.c. to Fig. 1.c. The large pittings to be seen in Fig. 1.c. do not form on the "discharged" fibers.

If we examine the effects of the oxidation process after 8 and 10 minutes, we see practically the same in the discharged fibers (Fig. 2.d. and 2.e) as we see in the grown fibers (Fig. 1.d. and 1.e.).

The final of the oxidation process seems similar if we compare Fig. 2.f. to Fig. 1.f., with both corresponding to an oxidation period of $15 \mathrm{~min}$.

\subsubsection{Inspection using confocal microscopy by reflection}

Figures 3.a. and 3.b. show the images obtained with confocal microscopy of the fibers studied in this work. They refer to the same samples as in figures 1.a. and 2.a., and we can see that there is a certain degree of irregularity on the discharged fiber's surface that was not to be seen on the grown fibers.

The information provided by confocal microscopy observation of fibers subjected to oxidation during 4 minutes is very interesting. If we compare Fig. 3.c. to Fig. 1.c. we see that the large pittings are a result of the complete elimination of a carbon grain while, if we compare Fig. 3.d. to Fig. 2.c. we can see that the pittings are located on boundaries between grains. This information is not deducible from the images provided by SEM microscopy.

After 8 min of oxidation, the width of the furrows between grains has been increased (Fig. 3.e. and 3.f).

This is because, with the use of confocal microscopy the same evolution of the oxidation process as with SEM microscopy was seen, but with optic microscopy we obtain information indicating that oxidation is preferential in areas located between grains.

\section{Discussion of the results}

From all the above, it appears that in the fabrication of VGCFs, two types of defects appear: some minute and homogeneously distributed, and others that are more voluminous, scarcer and more irregularly distributed.

This scheme coincides with that already known via research in nuclear materials, where it was proven that hydrogen locates itself inside graphite in two types of housing (Atsumi, 2003), some trappings inside some grains with an activation energy for the escape of hydrogen from these 2.6 4.4 eV accumulations, and other trappings located on the boundary between grains with $1.3 \mathrm{eV}$ energy. Therefore, the storage of hydrogen in these accumulations must be more intense.

This model of inhomogeneity in storage is more congruent with the storage model in a sp ${ }^{3}$ type carbon matrix, the phase constituted mostly by semi-amorphous carbons. In this matrix grainier sp2 type islets appear (Dasgupta et al., 1991).

The double structure of the network constituted by carbon atoms is well known. sp²-bonded carbon is localized in graphitic clusters which consist of four or more fused sixfold rings (Robertson, 1986). These clusters are connected by sp33-bonded carbon. 
Large voids in curved form where hydrogen is stored (Gupta and Srivastava, 2001) are also described in other graphite materials conformed in fibrous form.

We have also been able to check that when a graphite material is subjected to irradiation with neutrons (Atsumi et al., 1996), as the size of the grains diminishes, the hydrogen storage capacity increases as the number of boundaries increases. The content in hydrogen can be up to 20 times higher.

Therefore, both types of accumulations can be identified with the cavities shown in Fig. 1.c. To this end, a not too prolonged oxidation time freed the hydrogen from the accumulations on the boundaries, but not the hydrogen stored in the more voluminous accumulations located in the center of a grain.

The images obtained with CLSM are excellent proof of these models. For example, in Fig. 3.c. related to grown fibers, two types of accumulations can be clearly distinguished. With the same oxidation time, Fig. 3.d. shows us that in the case of discharged fibers the boundaries between grains are wider. This is due to the fact that there was take out of hydrogen in the discharged fibers samples were during the annealing.

This granular image of the skin of the VGCF coincides with that which was already known as regards its microstructure via previous studies conducted with transmission electron microscopy TEM. Therefore, it is known (Madroñero et al., 1996) that the fine structure consists of some $50 \mathrm{~nm}$ plates that compact to form curved plates of some $250 \mathrm{~nm}$ thickness and few micrometers wide (Madroñero et al., 1998).

These macrostructures now enter within the limit of optic microscopy, as we have seen through the images shown in Fig. 3.

Nonetheless, the possibilities of CLSM do not cease here as the use of ultraviolet radiation while functionalizing the surface of fibers with ammonium (Lacerda et al., 2007), would allow the obtaining of images with fluorescence that could enable the provision of additional information in the future.

In any case, the possibilities of a technique as simple as the CLSM are remarkable. In the present study is seen how the structure of fibers grown from a hydrocarbon gas is clearly different of the grain observed in commercial carbon fibers. As an example, in Fig. 4 is shown the microstructure of an ex-PAN carbon fiber, while Fig. 5 shows the features of an ex-Pitch fibre. Both types of fibers are very representative of the carbon fibers that are used currently in the industry to manufacture composite parts.

\section{Conclusions}

1. Regarding the aspect of oxidized fibers, it can be said that the oxidation of these materials occurs at the points of dye corrosion where the hydrogen is concentrated. Therefore, the corrosion figures can be used for drawing the location map of the hydrogen accumulations.

2. In the problem of hydrogen location in the fibers studied in this work, it is interesting to note the existence of two types of accumulations revealed by the studies performed to understand the behavior of carbons in nuclear reactors.

3. The utility of confocal laser optical microscopy as a powerful tool to allow tracking of the increase in width of the boundaries while being abandoned by the resorbed hydrogen has been proven to be effective. 


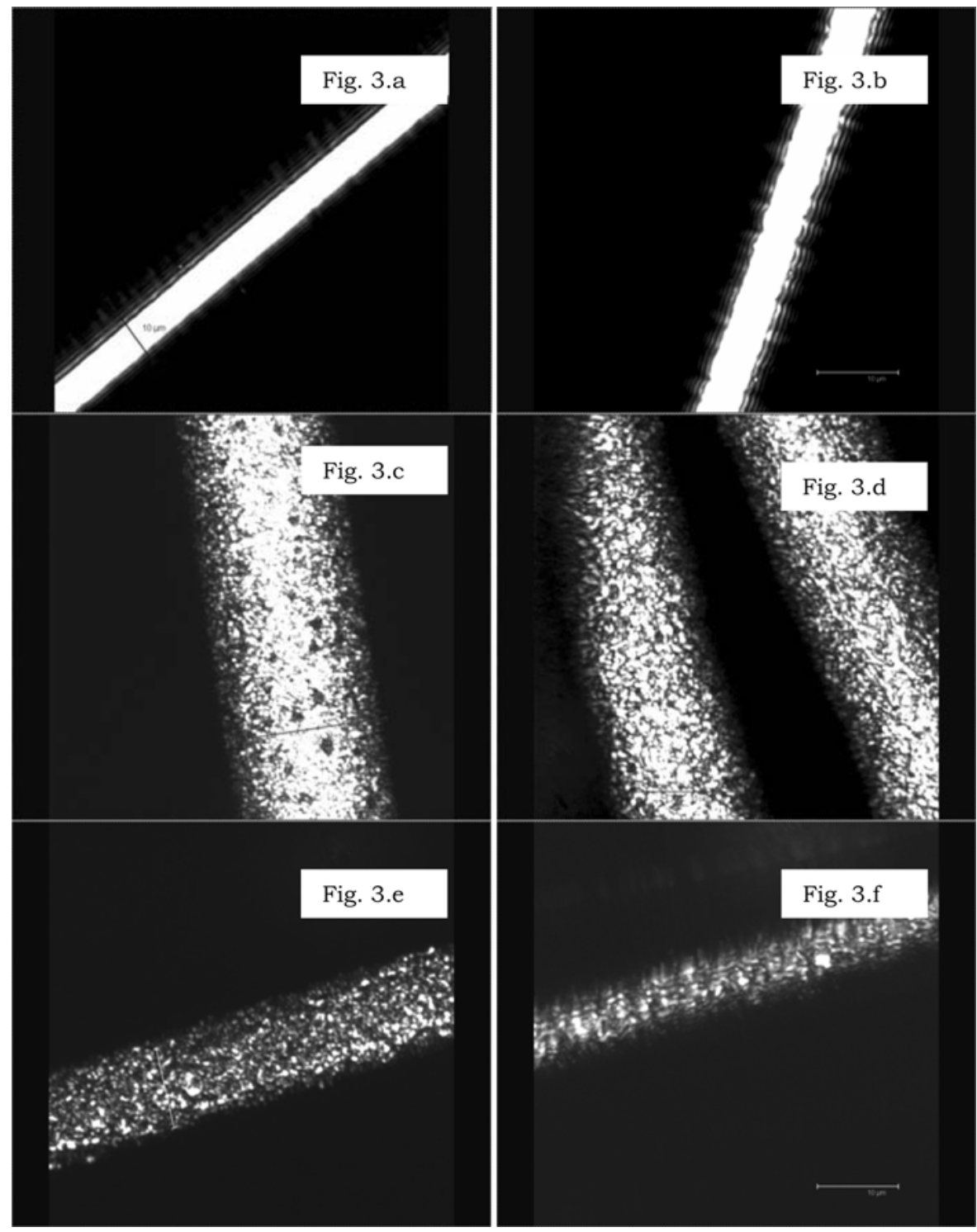

Fig. 3. Oxidation effects observed by confocal laser scanning microscopy. Scale bars: $3 a, 3 b$, $3 \mathrm{e}, 3 \mathrm{f},=10 \mu \mathrm{m} ; 3 \mathrm{c}=20 \mu \mathrm{m} ; 3 \mathrm{~d}=15 \mu \mathrm{m}$ 


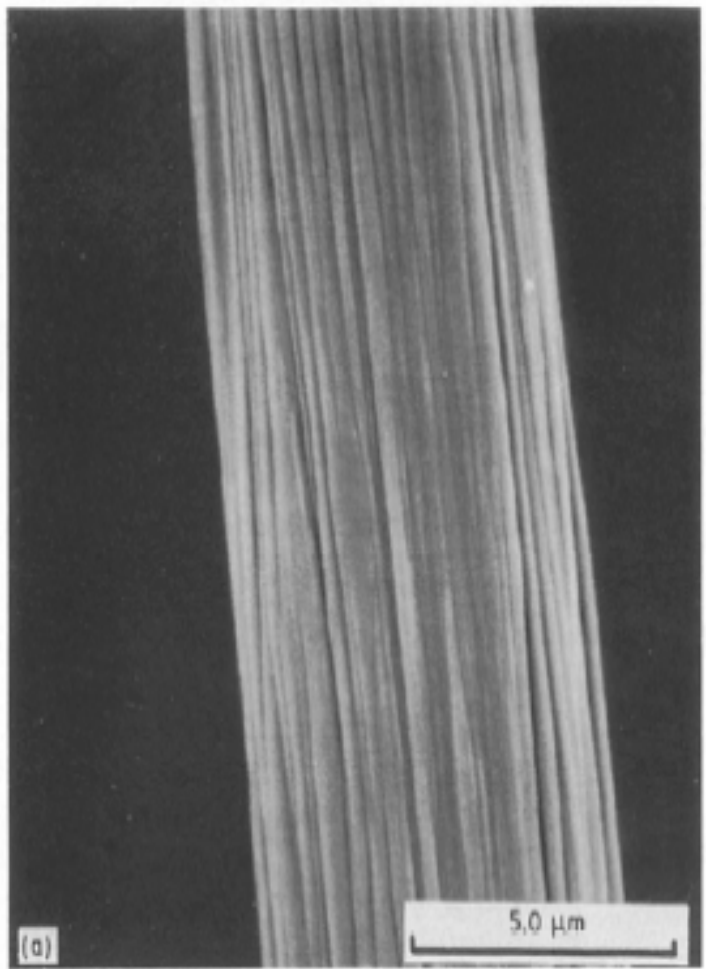

(a)

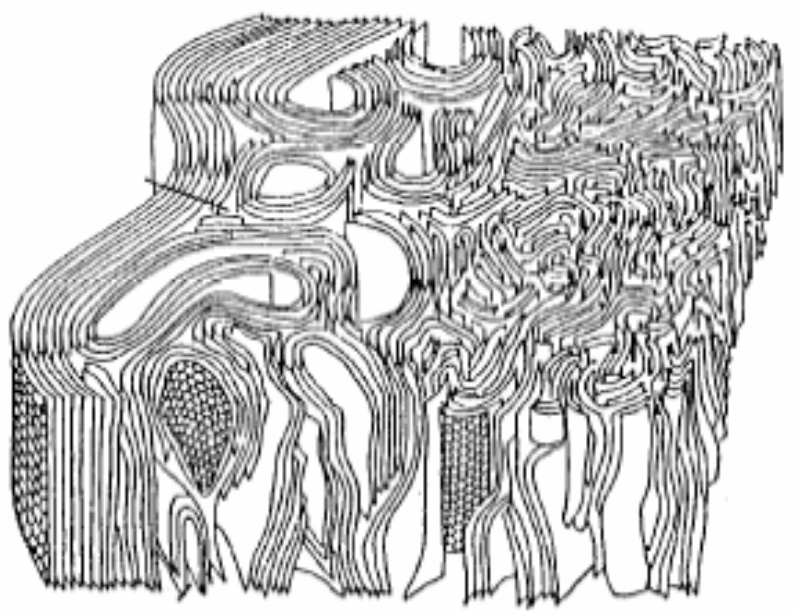

(b)

Fig. 4. Microstructure of a commercial carbon fibre type ex-PAN. $a=$ SEM micrograph, $b=$ inner architecture 

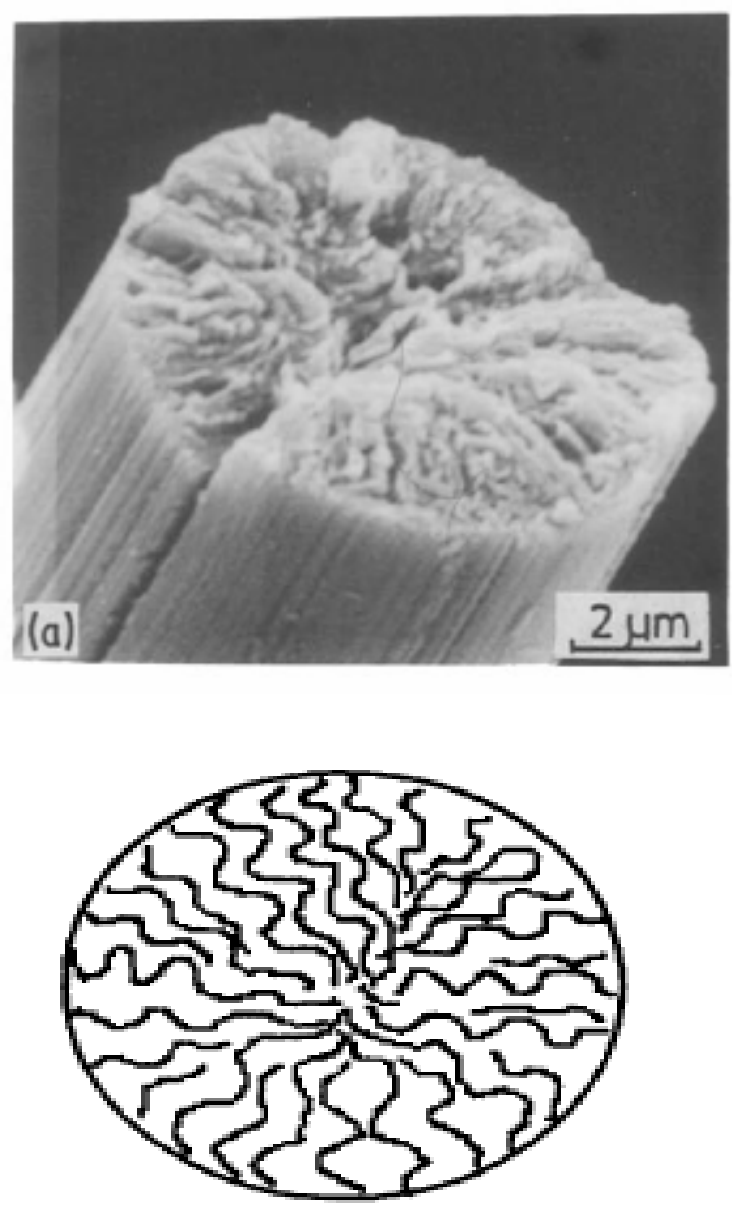

(b)

Fig. 5. Microstructure of a commercial carbon fibre type ex-pitch. a = SEM micrograph, $\mathrm{b}=$ inner architecture

4. The granular structure observed using confocal laser optical microscopy is in good agreement with the microstructure described in previous studies with TEM.

5. Unlike other carbonaceous materials that lose their hydrogen content slowly, the fibers studied in this work empty their deposits in a few minutes, provided they are annealed at the temperatures that have been utilized for thermal treatment processes in this study. 


\section{Acknowledgement}

This work was performed with funds of the Project "Tailoring electronic and phononic properties of nanomaterials; towards improved thermoelectricity (nanoTHERM)", included in the Consolider-Ingenio Program of the Spanish Ministry of Science and Innovation.

\section{References}

Alcañiz-Monge J, Román-Martinez MC. 2008. Upper limit of hydrogen adsorption on activated carbons at room temperature: A thermodynamic approach to understand the hydrogen adsorption on microporous carbons. Microporous Mesoporous Mater 112:510-520.

Atsumi H, Iseki M, Shikama T. 1996. Hydrogen behavior in carbon based materials and its neutron irradiation effect. J Nuclear Mater 233-237:1128-1132.

Atsumi H. 2003. Hydrogen retention in graphite and carbon materials under a fusion reactor environment. J Nuclear Mater 313-316:543-547.

Clarke A, Davidson N. 1993. Measurements of fibre direction in reinforced polymer composites. J Microsc 171:69-79.

Dasgupta D, Demichelis F, Tagliaferro A. 1991. Electrical conductivity of amorphous carbon and amorphous hydrogenated carbon. Phil Mag B 63:1255-1266.

Denis PA. 2008. Investigation of $\mathrm{H}_{2}$ physisorption on corannulene $\left(\mathrm{C}_{20} \mathrm{H}_{10}\right)$, tetraindenocorannulene $\left(\mathrm{C}_{44} \mathrm{H}_{18}\right)$, pentaindenocorannulene $\left(\mathrm{C}_{50} \mathrm{H}_{20}\right) . \mathrm{C}_{60}$, and their nitrogen derivates. J Phys Chem C 112:2791-2796.

Dillon AC, Heben MJ. 2001. Hydrogen storage using carbon adsorbents: Past, present and future. Appl Phys A-Mater Sci Process 72:133-142.

Gorbunov A, Jost O, Pompe W, Graff A. 2002. Solid-liquid-solid growth mechanism of single-wall carbon nanotubes. Carbon 40:113-118.

Gupta BK, Srivastava ON. 2001. Further studies on microstructural characterization and hydrogenation behaviour of graphitic nanofibres. Int J Hydrog Energy 26:857-862.

Kino GS, Corle TR. 1989. Confocal scanning optical microscopy. Phys Today 42:55-62.

Lacerda L, Pastorin G, Gathercole D, Budle J, Prato M, Bianco A, Kostarelos K. 2007. Intracellular traficking of carbon nanotubes by confocal laser scanning microscopy. Adv Mater 19:1480-1484.

Madroñero A. 1995. Possibilities for the vapour-liquid-solid model in the vapour-grown carbon fibre growth process. J Mater Sci 30: 2061-2066.

Madroñero A, Ariza E, Verdú M. 1995. Adsorption of hydrogen in carbon fibres made from polyacrylonitrile precursor, and vapour grown. Eur J Solid State Inorg Chem 32:1115-1127.

Madroñero A, Ariza E, Verdú M, Brandl W, Barba C. 1996. Some microstructural aspects of vapour-grown carbon fibres to disclose their failure mechanisms. J Mater Sci 31:6189-6193.

Madroñero A, Verdú M, Froten L, Domínguez M. 1997. A diffusion model for sword in sheath failure mode in vapour grown carbon fibers. Adv Perform Mater 4:305-315.

Madroñero A., Verdú M, Issi JP, Martin-Benito Romero J, Barba C. 1998. Study by a modified scanning electron microscope fractography of hydrogenation process in vapour grown carbon fibres. J Mater Sci 33:2079-2085. 
Merino C, Brandl W. 2003. Oxidation behaviour and microstructure of vapour grown carbon fibres. Solid State Sci 5:663-668.

Nechaev YUS. 2006. Hydrogen sorption by carbon nanostructures: Its nature, kinetics, and limiting capacity. Physics-Uspekhi 49:563-572.

Park C, Anderson PE, Chambers A, Tan CD, Hidalgo R, Rodriguez NM. 1999. Further studies of the interaction of hydrogen with graphite nanofibers. J Phys Chem B 103:10572-10581.

Robertson J. 1986. Amorphous carbon. Adv Phys 35:317-374.

Seifert G. 2004. Hydrogen on and in carbon nanostructures. Solid State Ion 168:265-269.

Serp PH, Madroñero A, Figueiredo JL. 1999. Production of vapour grown carbon fibres: Influence of the catalyst precursor and operating conditions. Fuel 78:837-844.

Takagi H, Hatori H, Soneda Y, Yoshizawa N, Yamada Y. 2004. Adsorptive hydrogen storage in carbon and porous materials. Mater Sci Eng B-Solid State Mater Adv Technol 108:143-147.

Veerasamy VS, Luten HA, Petrmichl RH, Thomsen SV. 2003. Diamonlike amorphous carbon coatings for large areas of glass. Thin Solid Films 442:1-10.

Yamada MK, Uo M, Ohkawa S, Akasaka T, Watari F. 2004. Non-contact surface morphology analysis of $\mathrm{CO} 2$ laser-irradiated teeth by scanning electron microscope and confocal laser scanning microscope. Mater Trans 45:1033-1040.

Zhou C, McGinn PJ. 2006. The effect of oxygen on the processing of mesocarbon microbeads to high-density carbon. Carbon 44:1673- 1681. 


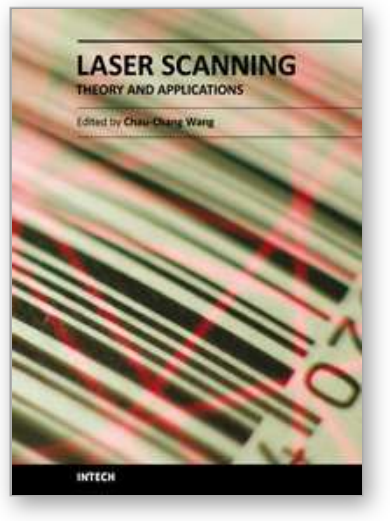

\author{
Laser Scanning, Theory and Applications \\ Edited by Prof. Chau-Chang Wang
}

ISBN 978-953-307-205-0

Hard cover, 566 pages

Publisher InTech

Published online 26, April, 2011

Published in print edition April, 2011

Ever since the invention of laser by Schawlow and Townes in 1958, various innovative ideas of laser-based applications emerge very year. At the same time, scientists and engineers keep on improving laser's power density, size, and cost which patch up the gap between theories and implementations. More importantly, our everyday life is changed and influenced by lasers even though we may not be fully aware of its existence. For example, it is there in cross-continent phone calls, price tag scanning in supermarkets, pointers in the classrooms, printers in the offices, accurate metal cutting in machine shops, etc. In this volume, we focus the recent developments related to laser scanning, a very powerful technique used in features detection and measurement. We invited researchers who do fundamental works in laser scanning theories or apply the principles of laser scanning to tackle problems encountered in medicine, geodesic survey, biology and archaeology. Twenty-eight chapters contributed by authors around the world to constitute this comprehensive book.

\title{
How to reference
}

In order to correctly reference this scholarly work, feel free to copy and paste the following:

Antonio Madroñero and Jose Ma Amo (2011). An Inspection of Some Hydrogenated Carbon Fibers by Scanning Electron Microscopy and Confocal Laser Scanning Microscopy, Laser Scanning, Theory and Applications, Prof. Chau-Chang Wang (Ed.), ISBN: 978-953-307-205-0, InTech, Available from: http://www.intechopen.com/books/laser-scanning-theory-and-applications/an-inspection-of-somehydrogenated-carbon-fibers-by-scanning-electron-microscopy-and-confocal-laser-

\section{INTECH}

open science | open minds

\section{InTech Europe}

University Campus STeP Ri

Slavka Krautzeka 83/A

51000 Rijeka, Croatia

Phone: +385 (51) 770447

Fax: +385 (51) 686166

www.intechopen.com

\section{InTech China}

Unit 405, Office Block, Hotel Equatorial Shanghai

No.65, Yan An Road (West), Shanghai, 200040, China 中国上海市延安西路65号上海国际贵都大饭店办公楼 405 单元

Phone: +86-21-62489820

Fax: $+86-21-62489821$ 
(C) 2011 The Author(s). Licensee IntechOpen. This chapter is distributed under the terms of the Creative Commons Attribution-NonCommercialShareAlike-3.0 License, which permits use, distribution and reproduction for non-commercial purposes, provided the original is properly cited and derivative works building on this content are distributed under the same license. 